Mycologia, 104(2), 2012, pp. 419-426. DOI: 10.3852/11-163

(C) 2012 by The Mycological Society of America, Lawrence, KS 66044-8897

\title{
Molecular phylogeny of Sydowiellaceae-resolving the position of Cainiella
}

\author{
Åsa Kruys ${ }^{1}$ \\ Systematic Biology, Department of Organismal Biology, \\ Evolutionary Biology Centre, Uppsala University, \\ Norbyvägen 18D, SE-752 36 Uppsala, Sweden \\ Lisa A. Castlebury \\ Systematic Mycology and Microbiology Laboratory, \\ USDA-ARS, Beltsville, Maryland 20705
}

Abstract: Cainiella is an ascomycete genus associated with arctic alpine plants. The systematic position of Cainiella has long been unclear, with current classifications placing the genus in either Sordariales or Xylariales. Our molecular results, based on $\mathrm{mtSSU}$, ITS and nLSU rDNA data, clearly show that the genus belongs in the Sydowiellaceae (Diaporthales). The study also includes new sequences of Sydowiellaceae and contributes to a better knowledge of the phylogenetic relationships of that family.

Key words: alpine, Ascomycota, Diaporthales, DNA-sequences, Fungi, Sordariales, systematics

\section{INTRODUCTION}

The cold-dominated environment of arctic alpine heaths harbors a number of interesting microfungi. Many of them are associated with a particular host plant and may even be restricted to a certain part of the host (Chlebicki 2002, Holm 1979, Holm and Holm 1980). The dwarf shrub genus Dryas is an attractive host, associated with more than 100 species of ascomycetes (Farr and Rossman 2010). One species that often occurs on Dryas octopetala is the type species of Cainiella, C. johansonii. Its small glabrous perithecia are immersed in the substrate but protrude with long hyaline to brown beaks on both upper and lower sides of leaves and petioles. It also occurs on other Dryas species and is widely distributed in arctic and alpine regions in the northern hemisphere.

The only other member of the genus to date is $C$. borealis. It occurs on branches of Cassiope tetragona and thus has an arctic circumpolar distribution. The glabrous, dark perithecia of $C$. borealis also are immersed in the substrate and have long beaks, but the perithecia are significantly larger than those of $C$. johansonii. The genus is further characterized by having unitunicate asci with non-amyloid apical rings (Nograsek 1990). The ascospores are one-septate,

Submitted 19 May 2011; accepted for publication 31 Aug 2011

${ }^{1}$ Corresponding author. E-mail: asa.kruys@ebc.uu.se hyaline to greenish yellowish, and eventually turn brown (Müller and von Arx 1962). The ascospores of C. borealis are described as having a finely pitted epispore (Barr 1959).

Müller (1956) introduced Cainiella (with C. johansonii as type) and placed it in the Sphaeriales. The classification of the genus since has alternated among closely related unitunicate families, for example Xylariaceae (Barr 1959), Amphisphaeriaceae (Müller and von Arx 1962), Cainiaceae (Vasilyeva 1987, 1998) and Hyponectriaceae (Kirk et al. 2008). Barr (1990) suggested a resemblance to Gelasinospora in the foveolate ornamentation of the ascospores and included Cainiella in the Sordariaceae (Sordariales), which is also the currently accepted position of the genus in the Outline of Ascomycota (Lumbsch and Huhndorf 2009). However Barr (1994) suggested Cainiella to be diaporthaceous while Vasilyeva (1998) separated the two species, transferring C. borealis to Sydowiella (Sydowiellaceae) and retaining C. johansonii in the Cainiaceae (Sordariales). This has not been adopted in current classifications (Kirk et al. 2008, Lumbsch and Huhndorf 2009).

The phylogenetic affinities of Cainiella have not been tested with DNA sequence data. The aim of this study therefore was to investigate whether Cainiella is closely related to members of Sordariales or Xylariales or if it belongs in a different taxon. Due to recent multigene phylogenies published by the research consortium Assembling the Fungal Tree of Life (AFTOL) and others (e.g. Schoch et al. 2009, Spatafora et al. 2006), a considerable amount of sequence data is available that should enable resolving the affinities of Cainiella.

\section{MATERIALS AND METHODS}

Taxon sampling.-In total 94 sequences were used for this study (see SuPPLEMENTARY TABLES I and II for source data and GenBank accession numbers). To test the two most recent classifications suggested for Cainiella (Kirk et al. 2008, Lumbsch and Huhndorf 2009) we aligned mtSSU rDNA and nLSU rDNA sequences of $C$. borealis and $C$. johansonii with sequences of the major clades of Sordariomycetidae and Xylariomycetidae obtained from GenBank. Leotia lubrica was used as outgroup based on its sister relationship to Sordariomycetes (Spatafora et al. 2006). To further study the phylogenetic relationships of Cainiella we compiled a nLSU rDNA dataset with diaporthalean taxa using Magnaporthe grisea as outgroup (Castlebury et al. 2002, Gryzenhout et al. 2006, Morocko and Fatehi 2007). Finally, we compiled an ITS rDNA dataset with focus on 


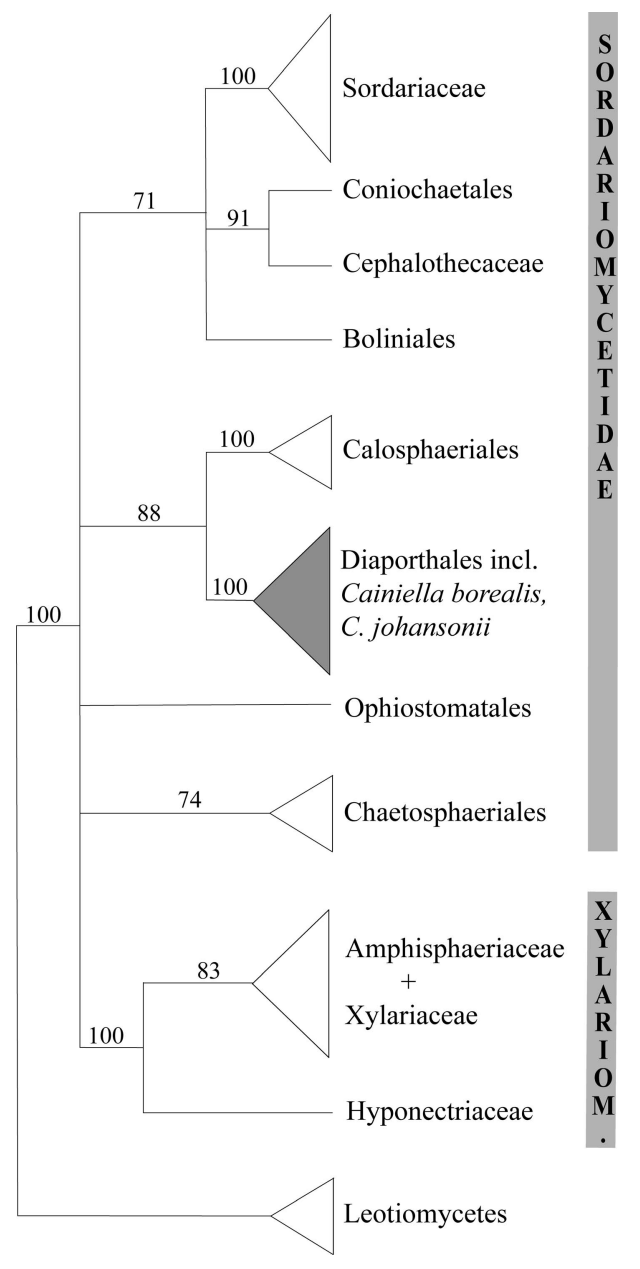

FIG. 1. Bootstrap consensus tree based on mtSSU and nLSU rDNA sequences. Numbers on branches are bootstrap support. Branches without significant support $(<70 \%)$ have been collapsed. GenBank accession numbers are provided (SuPPLEMENTARY TABLES I, II).

members of Sydowiellaceae. Diaporthe eres was chosen as outgroup because it is a more distantly related member of the same order (De Silva et al. 2009).

Fresh material of Cainiella borealis and C. johansonii was collected in the Swedish mountains 2008-2010. The Cainiella specimens that were used for extractions (SUPPLEMENTARY TABLE I) are preserved in the herbarium at the Botany Section of the Museum of Evolution at Uppsala University (UPS), Sweden. The following specimens were used for imaging, C. borealis: Sweden, Kruys 734, UPS (FIG. 5B-H), C. johansonii: Sweden, Kruys 732, UPS (FIG. 4C-E, H), Sweden, Kruys 733, UPS (FIG. 4B, G), Poland, A. Chlebicki, F 56257, KRAM (FIG. 4F).

DNA extraction, PCR amplification and sequencing.-DNA of fresh specimens was extracted with the EZNA Fungal DNA kit (Omega bio-tek, Doraville Georgia). The protocol for dry specimens was used according to the manufacturer's protocol, except that the material was homogenized for 3 min with a Mini-Beadbeater ${ }^{\mathrm{TM}}$ (BioSpec Products,
Bartlesville, Oklahoma). The sample was homogenized with $850-900 \mu \mathrm{L}$ buffer FG1 and $2.5 \mathrm{~mm}$ zirconia/silica beads (BioSpec Products, Bartlesville, Oklahoma). Double-stranded copies of the ITS-nLSU and mtSSU rDNA were obtained by polymerase chain reaction (PCR) amplifications with AccuPower ${ }^{\mathrm{TM}}$ PCR premix (BioNeer, Alameda, California) to which DNA extract, primers $(10 \mu \mathrm{M})$ and water was added according to manufacturer instructions. The ITS-nLSU rDNA was amplified with primers ITS1F/LR1 (Gardes and Bruns 1993, Vilgalys and Hester 1990) and LR0R/LR7 (Rehner and Samuels 1995, Vilgalys and Hester 1990), while mtSSU rDNA was amplified with MSU1/mrSSU3R (Zhou and Stanosz 2001, Zoller et al. 1999). In cases of weak amplification we used a nested PCR (Ekman 1999) with primers ITS1F/LR7, ITS1F/LR1 or MSU1/mrSSU3R as the first set of primers and LR0R/LR7, ITS1F/ITS4 and mrSSU1/mrSSU3R as the second set. Thermo-cycler conditions were initial denaturing at $94 \mathrm{C}$ for $5 \mathrm{~min}$ followed by five cycles of $94 \mathrm{C}$ for $30 \mathrm{~s}, 55 \mathrm{C}$ for $30 \mathrm{~s}$, $72 \mathrm{C}$ for $1 \mathrm{~min}$, and 30 cycles of $94 \mathrm{C}$ for $30 \mathrm{~s}, 52 \mathrm{C}$ for $30 \mathrm{~s}, 72 \mathrm{C}$ for $1 \mathrm{~min}$. PCR products were cleaned with MultiScreen HTS $^{\text {TM }}$ PCR plates (Millipore, Cork, Ireland). Sequencing reactions were performed by Macrogen Ltd. (Seoul, Korea) with these sequencing primers: ITS1F, ITS5, ITS4, LR3, LRAM1, LR3R, and LR7, mrSSU1, mrSSU2, mrSSU2R, mrSSU3R (Huhndorf et al. 2004, Rehner and Samuels 1995, Vilgalys and Hester 1990, White et al. 1990, Zoller et al. 1999).

Sequence alignment and phylogenetic analyses.-Sequence fragments were assembled and edited in Sequencher 4.8 (Gene Codes Corp., Ann Arbor, Michigan). The sequence alignments were done in Sequencher 4.8 and MacClade 4.08 (Maddison and Maddison 2005), optimized by eye and manually corrected when necessary. The alignments are deposited in TreeBASE (accession number S11557).

Support for branching topologies was evaluated for all three datasets with parsimony bootstrapping analyses in PAUP* 4.0b10 (Swofford 2002) with these parameters: 1000 replicates of bootstrapping, 10 random sequence addition heuristic searches, TBR branch swapping and multiple trees saved. Ambiguous positions, primer regions and uninformative characters were excluded from the analyses. Gaps were treated as missing data. The nLSU and the ITS dataset also were analyzed with Bayesian Markov chain Monte Carlo analyses conducted in MrBayes 3.2 (Ronqvist and Huelsenbeck 2003). The GTR + I + G model was the best-fit nucleotide substitution model for both the nLSU dataset and the ITS dataset, determined by the Akaike information criterion in Modeltest 3.7 (Posada and Crandall 1998). MCMC sampling was performed with two parallel runs, eight chains and every 100th tree saved. Sampling was halted when the critical value for the topological convergence diagnostic had reached 0.01 . The burn-in fraction was set to 0.25 , which corresponded to 305 trees in the nLSU rDNA dataset and 1798 trees in the ITS rDNA dataset. Significant support refers to bootstrap values (bs) $\geq 70 \%$ and posterior probability values $(\mathrm{pp}) \geq 95 \%$ (Alfaro et al. 2003, Hillis and Bull 1993).

The phylogeny of the ITS rDNA dataset was analyzed further with the parsimony criterion in PAUP* $4.0 \mathrm{~b} 10$ with 
these settings: 10000 random sequence addition heuristic searches, TBR branch swapping and multiple trees saved. A constrained parsimony analysis was performed to investigate a tree topology where the two Cainiella species are forced together in a monophyletic group, with all other taxa unresolved. The constraint analysis was performed with previous parsimony settings. Statistical support $(P<0.05)$ for the alternative tree topology was investigated with the Shimodaira-Hasegawa test (Shimodaira and Hasegawa 1999) implemented in PAUP*, using the resampling estimated log-likelihood method and 1000 bootstrap replicates.

\section{RESULTS}

This study resulted in five new Cainiella sequences and 15 new sequences of members of Sydowiellaceae (SupPlementary table I). The combined nLSU and mtSSU rDNA dataset of sequences from the major clades of Sordariomycetidae and Xylariomycetidae generated an alignment with 3795 (2218 + 1577) characters. Ambiguously aligned regions, introns and portions of the $5^{\prime}$ and $3^{\prime}$ ends were excluded, and $1971(1332+639)$ characters were included in the analysis. The number of parsimony informative sites versus variable sites of the nLSU rDNA partition was $270 / 415,147 / 248$ for the mtSSU rDNA, and 417/663 in total.

The bootstrap analysis of the combined nLSU and mtSSU rDNA shows that Cainiella borealis and $C$. johansonii are not closely related to either members of Sordariales or Xylariales (FIG. 1). Instead they group with Gnomonia gnomon (Diaporthales) with significant support (100\%).

The nLSU rDNA dataset generated an alignment with 1642 characters, of which 1311 were unambiguously aligned characters. The number of parsimony informative sites versus variable sites was 194/222. The Bayesian analysis of nLSU rDNA resulted in a majority rule consensus tree of 1832 sampled trees (FIG. 2). Cainiella johansonii is placed within a well supported Sydowiellaceae in both the Bayesian consensus tree and the bootstrap tree. Unfortunately we failed to sequence nLSU rDNA of $C$. borealis, despite several attempts. The bootstrap tree differed slightly from the Bayesian consensus tree in the details of the terminal topology of Sydowiellaceae. Cainiella, Rossmania, Sillia and Sydowiella form an unresolved group (75\%), with Chapeckia as their sister taxon in the bootstrap analysis, while Cainiella and Rossmania are sister taxa to an unresolved group with Chapeckia, Sillia and Sydowiella in the Bayesian consensus tree (pp 1.0).

The ITS rDNA dataset of Sydowiellaceae generated an alignment with 592 characters, of which 534 were unambiguously aligned. The number of parsimony informative sites versus variable sites was $157 / 201$. The Bayesian analysis resulted in a majority rule consensus tree of 10786 sampled trees (FIG. 3). The positions of $C$. borealis and $C$. johansonii are unresolved in the majority rule consensus tree, and the clade including them has low support (posterior probability 0.62 ). The parsimony analysis resulted in one most parsimonious tree with the tree length 437 steps, CI $=0.57$ and $\mathrm{RI}=0.74$. The two Cainiella species are paraphyletic in the most parsimonious tree and were placed in the same clade as in the majority rule consensus tree but with low (52\%) bootstrap support. The most parsimonious tree differed from the Bayesian consensus tree also in the position of $C$. nigrospora and $H$. berkeleyi. Chapeckia nigrospora is placed in between S. fenestrans and the C. galericulata clade while $H$. berkeleyi is sister taxon to the three $G$. fragariae in the parsimony analysis. The constrained topology analysis with $C$. borealis and $C$. johansonii forced together in one monophyletic group resulted in trees that were two steps longer than the most parsimonious one, but not significantly worse $(P=0.20-0.57)$.

\section{DISCUSSION}

The phylogenetic analyses of the three regions show that Cainiella belongs in Sydowiellaceae and that the family is a member of Diaporthales with high support (FIGS. 1-3), which is partly consistent with the classifications of Barr (1994) and Vasilyeva (1998). Diaporthales forms a strongly supported monophyletic group of plant-associated fungi. Typical features of diaporthalean fungi are the brown to black perithecia, usually with a long neck, that are immersed in a stroma or the substrate, lack of true paraphyses at maturity and unitunicate asci that float free within the centrum at maturity and that often have a conspicuous apical ring (Kirk et al. 2008, Rossman et al. 2007). The ascospores are variable and can be nonseptate to multiseptate or muriform, ellipsoidal to elongate, and hyaline or pale yellow to dark brown, and rarely black. Characteristics of the two Cainiella species agree with the description of the Diaporthales: dark, long-necked, immersed perithecia, deliquescing paraphyses, as well as asci with a refractive ring and septate spores. However we have not been able to confirm free-floating asci. The current outline of the Diaporthales (Rossman et al. 2007) includes nine families and is to a large extent based on molecular characteristics because several of the morphological features traditionally used for circumscribing families and genera have been shown to be homoplastic (Castlebury et al. 2002, Gryzenhout et al. 2006, Morocko and Fatehi 2007). 


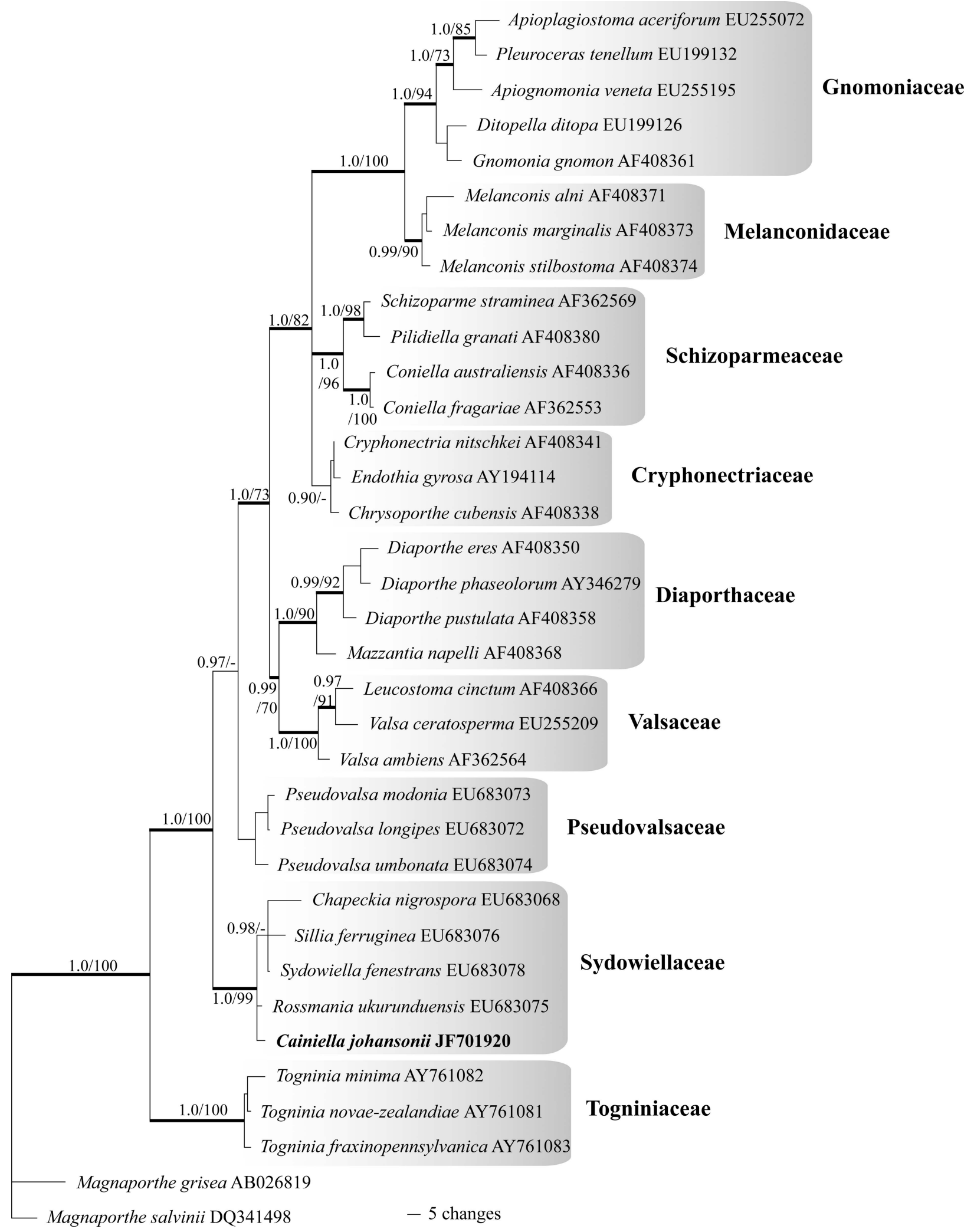

FIG. 2. Majority rule consensus tree from a Bayesian analysis based on nLSU rDNA sequences. Numbers on branches are posterior probabilities support followed by bootstrap support. - indicates support values below 0.9/70\%. Boldface lines indicate significant support of both algorithms. 
Kruys and Castlebury: Phylogeny of Sydowiellaceae

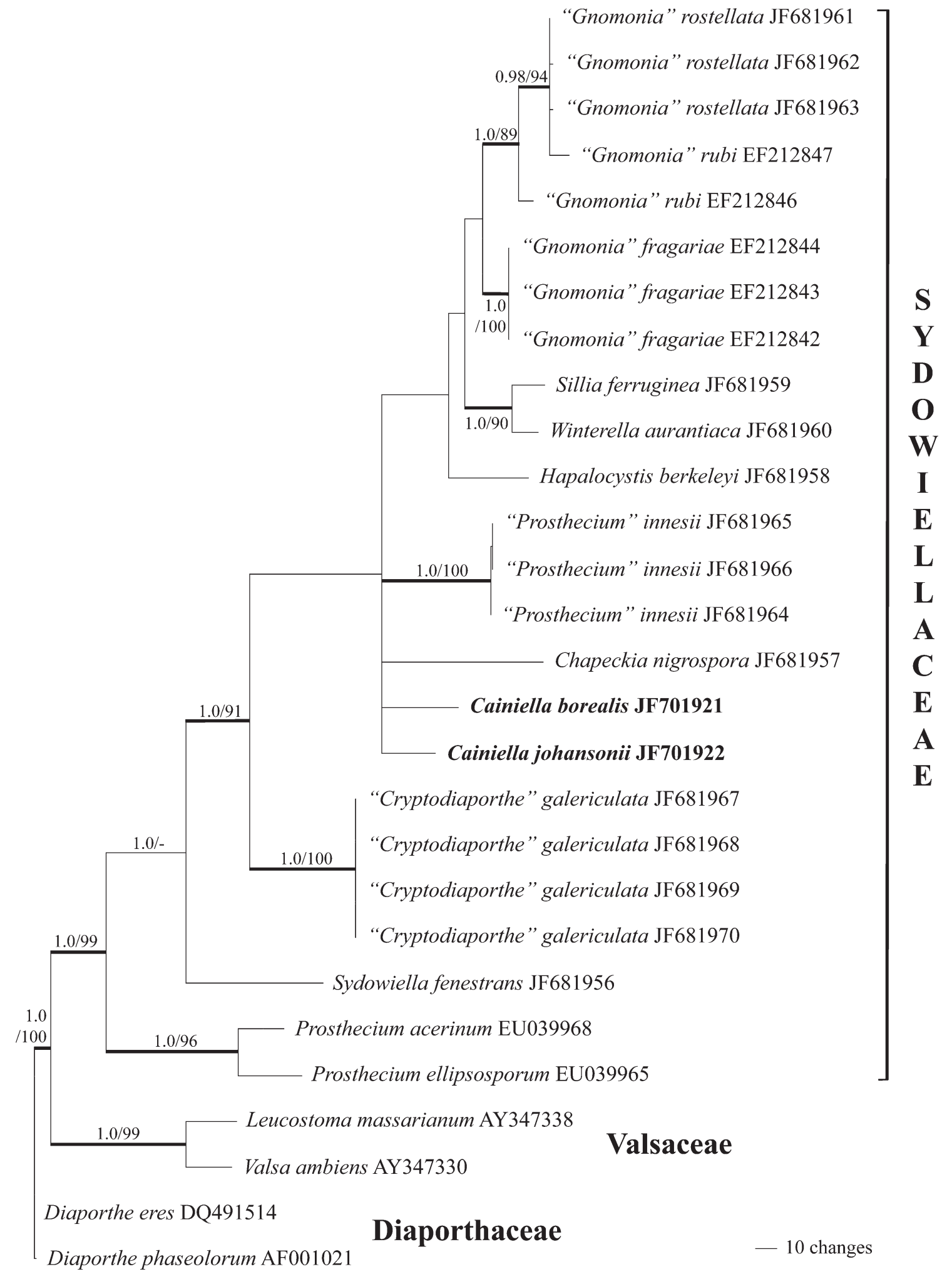

FIG. 3. Majority rule consensus tree from a Bayesian analysis based on ITS rDNA sequences. Numbers on branches are posterior probabilities support followed by bootstrap support. - indicates support values below 0.9/70\%. Boldface lines indicate significant support of both algorithms. 

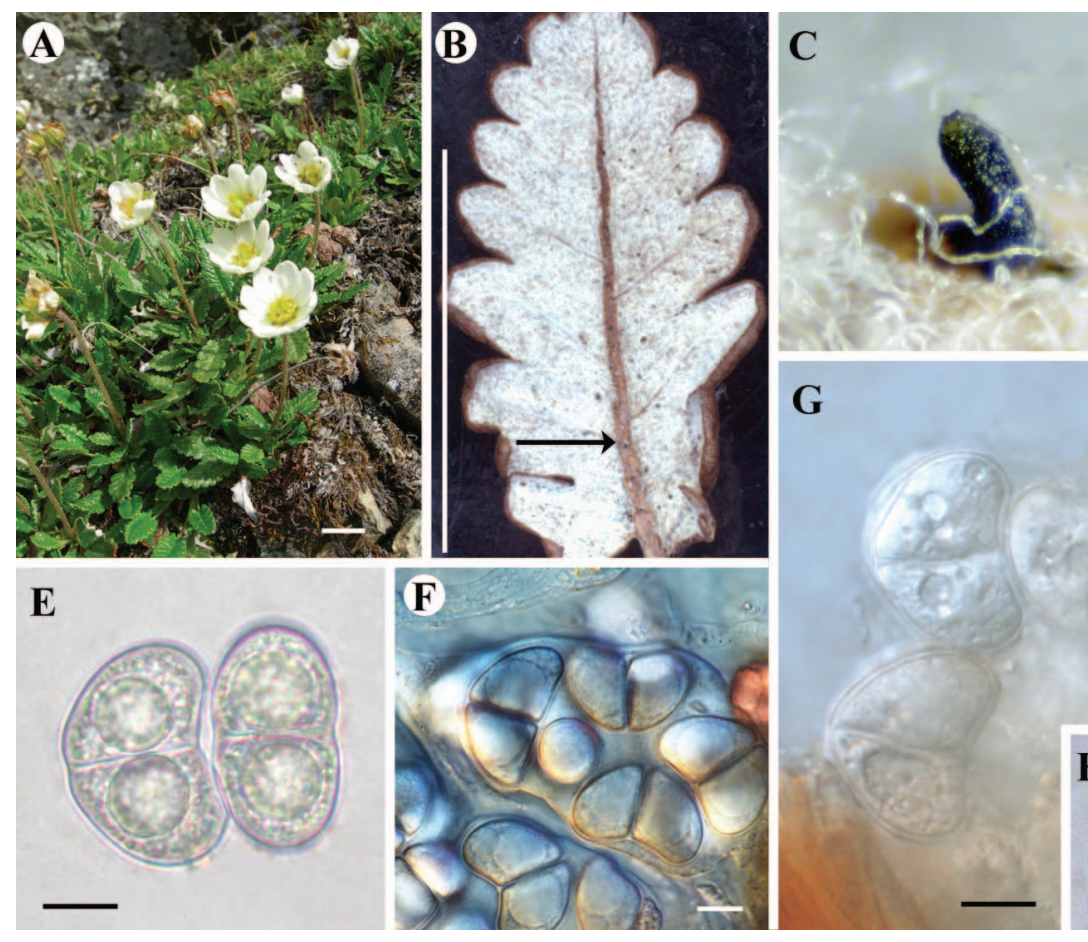

Fig. 4. Cainiella johansonii. A. The host plant Dryas octopetala. B. Perithecium on underside of decaying Dryas leaf. C. White Dryas hairs surround the long, protruding neck of an immersed perithecium. D. Ascus. E-G. Ascospores. H. Ascus top. C-E, H. Coll. Kruys 732, UPS. F. Coll. A. Chlebicki F 56257, KRAM. B, G. coll. Kruys 733, UPS. Bars: A, B = 1 cm, C = $100 \mu \mathrm{m}$, $\mathrm{D}-\mathrm{H}=10 \mu \mathrm{m}$.
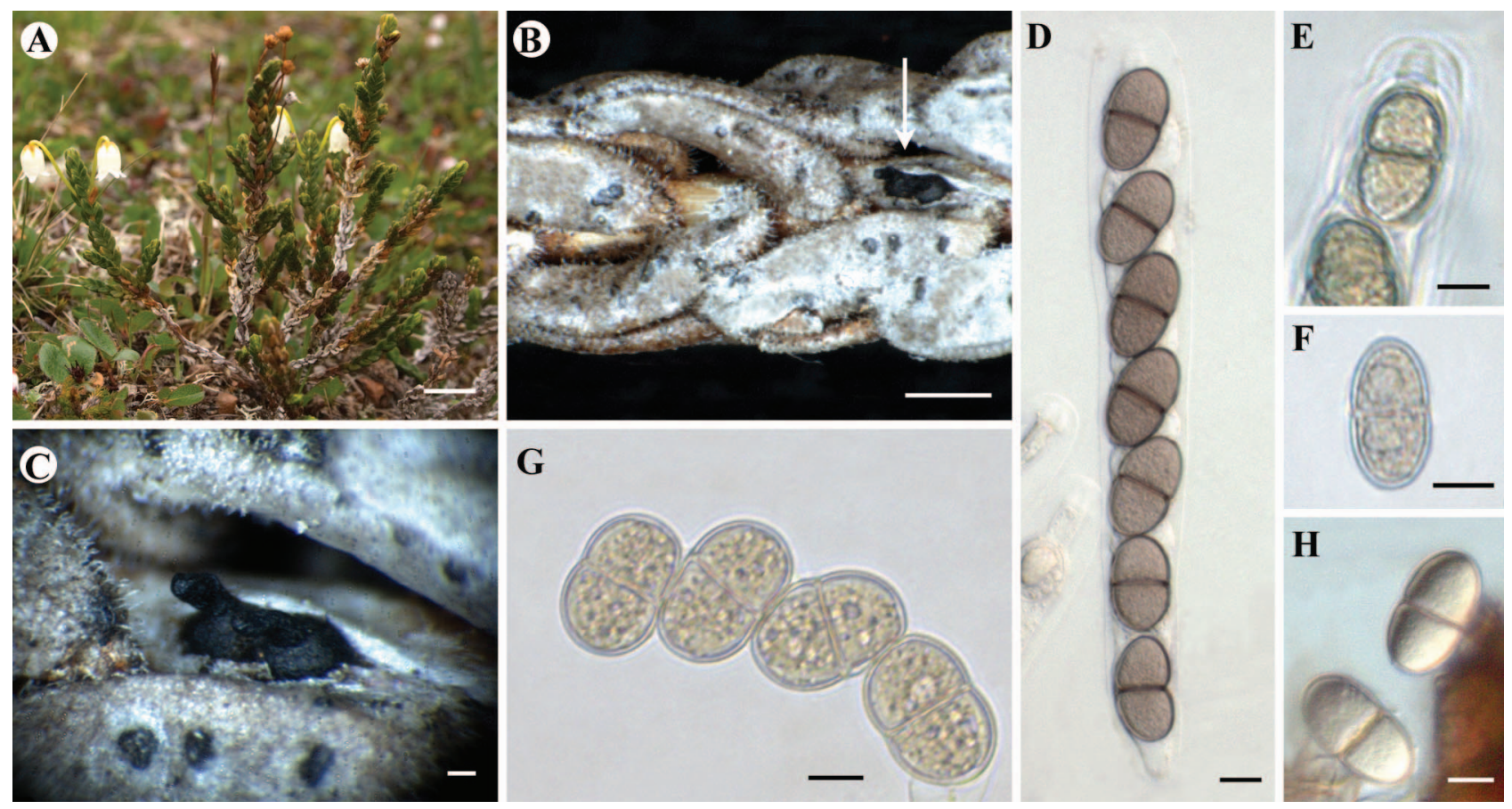

Fig. 5. Cainiella borealis. A. The host plant Cassiope tetragona. B. Perithecia on old decaying branches of C. tetragona. C. Ascomata of C. borealis often occur in pairs. D. Ascus with brown ascospores. E. Ascus top. F-H. Ascospores. B-H. Coll. Kruys 734, UPS. Bars: $\mathrm{A}=1 \mathrm{~cm}, \mathrm{~B}=1 \mathrm{~mm}, \mathrm{C}=100 \mu \mathrm{m}, \mathrm{D}-\mathrm{H}=10 \mu \mathrm{m}$. 
Sydowiellaceae is strongly supported in both our ITS and nLSU trees. The family currently includes the genera Cainiella, Chapeckia, Hapalocystis, Prosthecium, Rossmania, Sillia, Stegophora, Sydowiella, Winterella and several species previously placed in Cryptodiaporthe and Gnomonia. Sydowiellaceae is morphologically diverse and this in combination with unresolved phylogenetic relationships within the family makes it unfeasible to determine the closest relatives of Cainiella at present. The family comprises both parasites and saprobes, living on herbaceous, dicotyledonous plants and hardwood trees. Cainiella johansonii appears on both the green and the dead leaves and petioles of Dryas and may have some parasitic association with its host plant, while Cainiella borealis was found only on old browngray branches of Cassiope tetragona and is probably a saprobe.

Cainiella borealis and C. johansonii are morphologically alike in a number of characters, namely the growth habit, the shape of the ascomata, asci with multiple apical rings and the one-septate, hyalinebrown spores with a thick epispore and a slight constriction at the septum. The type $C$. johansonii has significantly smaller perithecia, while the perithecia of C. borealis often are confluent in pairs. Cainiella johansonii has broader asci and ascospores than $C$. borealis, and the spores are kidney-shaped. The ascospores of $C$. borealis are ellipsoidal, and we found the epispore to be smooth although it has been described as finely pitted (Barr 1959, Holm 1975, Müller and von Arx 1962). Both species have guttulate spores and the spore content is refractive and appears greenish or yellowish. The spores become brown with age (Müller and von Arx 1962), and this change seems to develop at a very late stage because Barr (1959) and Holm (1975, 1979) could not confirm it and we found brown spores in only one old perithecium of $C$. borealis (FIG. 5D) and in one of C. johansonii. Müller and von Arx (1962) also described the ascospores in both species with terminal germ pores, but we are doubtful of this observation. It has not been verified by other authors (Barr 1959; Holm 1975, 1979; Nograsek 1990) or in our study, and germ-pores are unusual among the diaporthalean fungi.

Cainiella borealis and C. johansonii are not monophyletic in the ITS analysis, but the results of the constraint analysis and the S-H test does not reject the possibility that the two species are monophyletic. There is also morphological support for $C$. borealis and $C$. johansonii to remain in one genus, and because our data do not place either within any existing genus it is not warranted at this time to transfer any of the two species to any other genus.

\section{ACKNOWLEDGMENTS}

We thank Amy Rossman for fruitful comments on this manuscript. We thank Stefan Ekman, Thomas Læssøe and Jens H. Petersen for the loan of a microscope with camera and Andrzej Chlebicki for letting us use his images (FIG. 4A, F). Thanks also to Sven-Ove Nyberg for excellent help in the field. This study is financed by the Swedish Taxonomy Initiative (dha 34/07 1.4) and the Helge Ax:son Johnson foundation.

\section{LITERATURE CITED}

Alfaro ME, Zoller S, Lutzoni F. 2003. Bayes or bootstrap? A simulation study comparing the performance of Bayesian Markov chain Monte Carlo sampling and bootstrapping in assessing phylogenetic confidence. Mol Biol Evol 20:255-266, doi:10.1093/molbev/ msg028

Barr ME. 1959. Northern pyrenomycetes I. Canadian Eastern Arctic. Contrib inst bot úniv Montréal 73:5103.

- 1990. Prodromus to nonlichenized, pyrenomycteous members of class Hymenoascomycetes. Mycotaxon 39:43-184.

- 1994. Notes on the Amphisphaeriaceae and related families. Mycotaxon 51:191-224.

Castlebury LA, Rossman AY, Jaklitsch WJ, Vasilyeva LN. 2002. A preliminary overview of the Diaporthales based on large subunit nuclear ribosomal DNA sequences. Mycologia 94:1017-1031, doi:10.2307/3761867

Chlebicki A. 2002. Biogeographic relationships between fungi and selected glacial relict plants. The use of hostfungus data as an aid to plant geography on the basis of material from Europe, Greenland and northern Asia. Monogr Bot 90:1-230.

De Silva H, Castlebury LA, Green S, Stone JK. 2009. Characterization and phylogenetic relationships of Anisogramma virgultorum and $A$. anomala in the Diaporthales (Ascomycota). Mycol Res 113:73-81, doi:10.1016/j.mycres.2008.08.008

Ekman S. 1999. PCR optimization and troubleshooting, with special reference to the amplification of ribosomal DNA in lichenized fungi. Lichenologist 31: 517-531.

Farr DF, Rossman AY. 2010. Fungal databases, Systematic Mycology and Microbiology Laboratory, ARS, USDA. Retrieved 17 Dec 2010 from/fungaldatabases/

Gardes M, Bruns TD. 1993. ITS primers with enhanced specificity for basidiomycetes-application to the identification of mycorrhizae and rusts. Mol Ecol 2:113-118, doi:10.1111/j.1365-294X.1993.tb00005.x

Gryzenhout M, Myburg H, Wingfield BD, Wingfield MJ. 2006. Cryphonectriaceae (Diaporthales), a new family including Cryphonectria, Chrysoporthe, Endothia and allied genera. Mycologia 98:239-249, doi:10.3852/ mycologia.98.2.239

Hillis DM, Bull JJ. 1993. An empirical test of bootstrapping as a method for assessing confidence in phylogenetic analysis. Syst Biol 42:182-192. 
Holm L. 1975. Taxonomic notes on ascomycetes VIII. Microfungi on Cassiope tetragona. Svensk Bot Tidskr 69: 143-160.

. 1979. Microfungi on Dryas. Bot Notiser 132:77-92.

, Holm K. 1980. Microfungi on Cassiope (Harrimanella) hypnoides. Norweg J Bot 27:179-184.

Huhndorf SM, Miller AN, Fernández FA. 2004. Molecular systematics of the Sordariales: the order and the family Lasiosphaeriaceae redefined. Mycologia 96:368-387, doi: $10.2307 / 3762068$

Kirk PM, Cannon PF, Minter DW, Stalpers JA. 2008. Dictionary of the Fungi. 10th ed. Wallingford, UK: CAB International. $784 \mathrm{p}$.

Lumbsch HT, Huhndorf SM. 2009. Outline of Ascomycota 2009 Part 1. Myconet 14:1-42.

Maddison WP, Maddison DR. 2005. MacClade 4: analysis of phylogeny and character evolution. Sunderland, Massachusetts: Sinauer Associates.

Morocko I, Fatehi J. 2007. Molecular characterization of strawberry pathogen Gnomonia fragrariae and its genetic relatedness to other Gnomonia species and members of Diaporthales. Mycol Res 111:603-614, doi:10.1016/j.mycres.2007.03.012

Müller E. 1956. Über die neue sphaeriale Gattung Cainiella. Sydowia 10:118-121.

— Pyrenomyceten. Beitrage zur Kryptogamenflora der Schweiz. Sydowia 11:1-922.

Nograsek A. 1990. Ascomyceten auf Gefässpflanzen der Polterseggenrasen in den Ostalpen. Bibliotheca Mycol 133:1-271.

Posada D, Crandall KA. 1998. Modeltest: testing the model of DNA substitution. Bioinformatics 14:817-818, doi:10.1093/bioinformatics/14.9.817

Rehner SA, Samuels GL. 1995. Molecular systematics of the Hypocreales-a teleomorph gene phylogeny and the status of their anamorphs. Can J Bot 73:816-823, doi:10.1139/b95-327

Ronquist F, Huelsenbeck JP. 2003. MrBayes 3: Bayesian phylogenetic inference under mixed models. Bioinformatics 19:1572-157, doi:10.1093/bioinformatics/ btg 180

Rossman AY, Farr DF, Castlebury LA. 2007. A review of the phylogeny and biology of the Diaporthales. Mycoscience 48:135-144, doi:10.1007/s10267-007-0347-7

Schoch CL, Sung GH, Lopez-Giraldez F, Townsend JP, Miadlikowska J, Hofstetter V, Robbertse B, Matheny PB, Kauff F, Wang Z, Gueidan C, Andrie RM, Trippe K, Ciufetti LM, Wynns A, Fraker E, Hodkinson BP, Bonito G, Groenewald JZ, Arzanlou M, de Hoog GS, Crous PW, Hewitt D, Pfister DH, Peterson K, Gryzenhout M, Wingfield MJ, Aptroot A, Suh SO, Blackwell M, Hillis
DM, Griffith GW, Castlebury LA, Rossman AY, Lumbsch HT, Lucking R, Budel B, Rauhut A, Diederich P, Ertz D, Geiser DM, Hosaka K, Inderbitzin P, Kohlmeyer J, Volkmann-Kohlmeyer B, Mostert L, O’Donnell K, Sipman H, Rogers JD, Shoemaker RA, Sugiyama J, Summerbell RC, Untereiner W, Johnston PR, Stenroos S, Zuccaro A, Dyer PS, Crittenden PD, Cole MS, Hansen K, Trappe JM, Yahr R, Lutzoni F, Spatafora JW. 2009. The Ascomycota tree of life: a phylum-wide phylogeny clarifies the origin and evolution of fundamental reproductive and ecological traits. Syst Biol 58:224-239, doi:10.1093/sysbio/syp020

Shimodaira H, Hasegawa M. 1999. Multiple comparisons of log-likelihoods with applications to phylogenetic inference. Mol Biol Evol 16:1114-1116.

Spatafora JW, Sung GH, Johnson D, Hesse C, O'Rourke B, Serdani M, Spotts R, Lutzoni F, Hofstetter V, Miadlikowska J, Reeb V, Gueidan C, Fraker E, Lumbsch T, Lücking R, Schmitt I, Hosaka K, Aptroot A, Roux C, Miller AN, Geiser DM, Hafellner J, Hestmark G, Arnold AE, Budel B, Rauhut A, Hewitt D, Untereiner WA, Cole MS, Scheidegger C, Schultz M, Sipman H, Schoch CL. 2006. A five-gene phylogeny of Pezizomycotina. Mycologia 98:1018-1028, doi:10.3852/mycologia.98.6.1018

Swofford DL. 2002. PAUP* 4.0b10: phylogenetic analysis using parsimony (*and other methods). Sunderland, Massachusetts: Sinauer Associates.

Vasilyeva LN. 1987. Pirenomicety i Lokuloaskomicety severa Dal'nego Vostoka. Leningrad, Russia: Nauka. 254 p.

- 1998. Plantae non vasculares, Fungi et bryopsidae orientis extremi Rossica, Fungi. T 4. Pyrenomycetidae et Loculoascomycetidae. St Petersburg, Russia: Nauka. 417 p.

Vilgalys R, Hester M. 1990. Rapid genetic identification and mapping of enzymatically amplified ribosomal DNA from several Cryptococcus species. J Bacteriol 172:42384246.

White TJ, Bruns T, Lee S, Taylor JW. 1990. Amplification and direct sequencing of fungal ribosomal RNA genes for phylogenetics. In: Innis MA, Gelfand DH, Sninsky JJ, White TJ, eds. PCR protocols: a guide to methods and applications. New York: Academic Press. p 315322.

Zhou S, Stanosz GR. 2001. Primers for amplification of mtSSU rDNA and a phylogenetic study of Botryosphaeria and associated anamorphic fungi. Mycol Res 105:1033-1044, doi:10.1016/S0953-7562(08)61965-6

Zoller S, Scheidegger C, Sperisen C. 1999. PCR primers for the amplification of mitochondrial small subunit ribosomal DNA of lichen-forming ascomycetes. Lichenologist 31:511-516. 